\title{
Design Strategies and LCA of Alternative Solutions for Resilient, Circular, and Zero-Carbon Urban Regeneration: A Case Study
}

\author{
Andrea Campioli, Elena Mussinelli, Monica Lavagna and Andrea Tartaglia
}

\begin{abstract}
This paper analyzes the results and the methods applied to an environmental research activity within a team participating in the $\mathrm{C} 40$ reinventing cities call of the Municipality of Milan. The aim was to support the decision-making process in the selection of material, construction, design choices oriented toward the circularity of resources, and the reduction of impacts connected to the greenhouse effect (carbon footprint), through the verification of environmental performances (life-cycle assessment) of alternative solutions and to identify an innovative and efficient environmental model for low carbon buildings.
\end{abstract}

Keywords Zero carbon development $\cdot$ Life-cycle assessment $\cdot$ Carbon footprint • Circular building $\cdot$ Resilient cities

\section{The Scenario}

In 2005, the network C40 Cities Climate Leadership Group was established to cope against the growing environmental issues derived by the traditional models of city development. The idea was to form a collaboration among large cities to implement shared policies and common action able to produce a measurable reduction in greenhouse gases (GHG) and in the risks deriving from climate change. Starting with the representatives of eighteen megacities, after only one year the network included 40 cities, giving the name to the network. ${ }^{1}$ Nowadays, total affiliated cities are over ninety of which more than $70 \%$ have already activated programs and actions to cope

\footnotetext{
${ }^{1}$ The major activities of the network aim to: "connect city officials with their peers around the world to help deliver solutions to climate challenges; inspire innovation by show casing the ideas and solutions of leading global cities; advise city peers based on experience with similar projects and policies; influence national and international policy agendas and drive the market by leveraging the collective voice of cities" (source: https://www.c40.org/networks).
}

A. Campioli ( $\varangle) \cdot$ E. Mussinelli $\cdot$ M. Lavagna $\cdot$ A. Tartaglia

Architecture, Built Environment and Construction Engineering-ABC Department, Politecnico di Milano, Milan, Italy

e-mail: andrea.campioli@polimi.it

(C) The Author(s) 2020

S. Della Torre et al. (eds.), Regeneration of the Built Environment

from a Circular Economy Perspective, Research for Development,

https://doi.org/10.1007/978-3-030-33256-3_20 
with climate change. Inside this scenario in 2018, starting from a former experience, carried out by the Municipality of Paris, 14 cities $^{2}$ of the network selected 31 underused sites to be used for an international competition named Reinventing Cities. The competition's goal was to involve developers, designers, and environmental experts in the definition of projects of interventions capable of reducing to zero the carbon footprint deriving from the construction/reconstruction and the use of these areas. In fact, the project groups, which would have bought the area in the event of victory, would have been selected with respect to the project's contents of the proposal evaluated in view of the capacity to respond to climate change and to favor the evolution of the territories in which they were located. The organization of the competition provided a set of guidelines that were the same for all the sites. The guidelines addressing the design of a carbon-free project stressed ten elements to be aware of or challenges ${ }^{3}$ which would have also been the criteria for the evaluation of the various proposals. The challenges interpreted the issue of carbon footprint and resilience with a truly wide view correctly obliging the groups to work and think in view of a life-cycle approach. The city of Milan participated in identifying five sites of different sizes. The ABC Department was involved as the environmental expert ${ }^{4}$ of a group ${ }^{5}$ competing for the transformation of the area of via Serio: an area of almost 0.5 ha, property of the Municipality and partially used as a parking lot. The project proposes an innovative residence solution consisting of minimal housing modules, intended for students and young workers.

\footnotetext{
${ }^{2}$ The cities involved in the call were: Auckland, Chicago, Houston, Madrid, Milano, Montréal, Oslo, Paris, Portland, Reykjavík, Rio de Janeiro, Salvador, San Francisco, and Vancouver.

${ }^{3}$ The ten challenges as defined in the guidelines were: building energy efficiency and a supply of clean energy; sustainable materials management and circular economy; green mobility; resilience and adaptation; new green services for the site and the neighborhood; green growth and smart cities; sustainable water management; biodiversity, urban re-vegetation and agriculture; inclusive actions and community benefits; innovative architecture and urban design.

${ }^{4}$ The research group from the ABC Dept. was composed of: environmental design, urban scale studies and NBS-Elena Mussinelli, Andrea Tartaglia (general coordinator), Giovanni Castaldo, Davide Cerati; environmental performances, LCA and carbon footprint-Andrea Campioli, Monica Lavagna, Tecla Caroli, Anna Dalla Valle, and Serena Giorgi.

${ }^{5}$ The team for the project named Proxima was composed of: promoter-Energa Group S.r.l.; architectural design and coordination—Joseph Di Pasquale Architects S.r.l.; environmental expert-ABC Dept., Politecnico di Milano; engineering-Studio Tecneas, Siemens S.p.A.; technical specialist project consultant-Siemens S.p.A. Building Technologies Division; geology and geothermal energy—Dr Umberto Puppini; fire design—Building S.r.l.s; App interface design—IED—Istituto Europeo di Design S.p.A.; operating/management partner-Dovevivo S.p.A.; graphic representation-arch. Emanuela Sara Cidri; administrative and legal advisor-Bertacco Law Firm; financial management—Prothea S.r.l.; financial intermediaries—Crowdfunding Walliance S.r.l., Fundera S.r.l.; project partners for Sharing mobility-Axpo energy solutions Italia S.p.A.; project partners for environment-LegambienteLombardiaOnlus; project partner for the supply of wooden structures-Rikohišed.o.o.
} 


\section{The Environmental Approach}

As environmental expert, the research group from the ABC Department had the role of supporting the design process identifying and selecting approaches, tools and solutions able to guarantee the highest environmental performances in the intervention throughout its entire life cycle. Thus, it was a significant opportunity to transfer theoretical models of analysis and evaluation into a real situation carrying out the activity in a continuous confrontation and collaboration with the typical stakeholders that characterize design, construction and management activities in the real estate area.

The aim was to go beyond the state-of-the-art about carbon footprint issue in buildings, adopting, experimenting, and testing innovative solutions. As a starting point, of course, the selected environmental approach took into account elements/indicators that are typically considered in the various environmental certifications with voluntary adhesion present in the Italian market (e.g., ITACA protocol, LEED certification, CasaClima, and Well) paying attention to elements such as user well-being, water and other natural resources management, energy and pollutant consumption, materials, site features, and integration in the context, relations, and mobility systems. All of these issues were addressed in order to reach levels of excellence with respect to the possibilities provided by technologies and indeed by introducing solutions of strong process and product innovation. In addition to this, in the environmental assessment model proposed, the users and their behavior during the use phase were also introduced as fundamental elements both to measure the real impacts of the intervention and to allow, through continuous monitoring and rewarding solutions, the progressive improvement of the "building-human being" system with respect to the issues of environmental sustainability, the use of resources, the response to climate change, quality of life, and the construction of a "resilient community."

Therefore, the final choice was to launch an ambitious challenge in which the environmental values of building interventions, deriving from human being-building interaction, would have been really monitored and verified also during the use phase to support the introduced tools for the correction and continuous improvement of environmental performance. This was done because the measurements made once the buildings are in use normally show a substantial difference between design forecasts in terms of consumption/impact up to $200 \%$ (Lehmann et al. 2017). Moreover, the human factor or "human behavior" is normally not considered or assessed in environmental protocols, even if human behavior in energy consumption alone can produce variations with respect to design forecasts of between 10 and $80 \%$ (van Dronkelaar et al. 2016).

For this reason, in order to reduce to the minimum the environmental impactswith the ultimate goal of eliminating any impact over a time span of 50 years, which was the duration defined for the project during the structuring phase of the initiativea number of specific solutions were introduced in the final project. 
In particular, an integrated management system of the two-way relationships between user/building, operator/building, and operator/user was introduced to monitor the performance of the building and living behavior. This was carried out through the sensorized building and typological system, integrated through a suitable software platform. Moreover, living devices are directly linked to each individual user, to their preferences and behavior, which group together short-term functions and technologies that can be implemented during each maintenance/replacement/regeneration intervention with components with a lower environmental impact, thus gradually improving the overall performance of the whole building system (building system as a dynamic reality) during its life cycle. The monitoring system (defined to involve indoor areas, open spaces, and ways of use) is an integral part of the environmental protocol and cannot be eliminated in either the project or during use, as it is also used to define the economic agreements between a property and its housing services manager, and can also be used to control and optimize management costs.

Furthermore, a complete integration between nature-based solutions (NBS) (tree planting, bioswales, rain gardens, green roofs, and green walls) and technical and construction solutions was decided in order to pursue project goals.

\section{Life-Cycle Assessment to Support Design Choices}

To achieve the objective required by the call for a zero carbon settlement throughout the entire life cycle, in the different phases of the decisional process the design choices were subjected to verification of the carbon footprint, using the LCA methodology (EN 15978:2011).

In the preliminary phase, the research group indicated to the design team on which elements it was important to focus attention, in view of achieving such an ambitious result. The elements that have the greatest role on environmental impacts are the supporting structure of the building (for the huge amount of material used) and the energy aspects (consumption and type of energy carriers used). Hence, the choice of materials for the building's supporting structure and the control of energy aspects (design strategies aimed at reducing consumption, through the use of a high thermal performance envelope, and the installation of systems for energy production from renewable sources) were considered as priorities. With the attention being focused only on the carbon footprint indicator, therefore of $\mathrm{CO}_{2}$ equivalent emissions, the only way to compensate for the impacts of materials production and building construction is to use wood (or resources of the renewable plant supply chain), which allow to also include carbon absorption during plant growth into the carbon footprint balance. Several studies demonstrated the GHG emissions reduction achieved by timber structure in buildings (Fouquet et al. 2015; Skullestad et al. 2016). The storage of carbon in the wood can be considered in the balance as an advantage only if it is assumed that at the end of the building's service life the wood is not burnt (waste-to-energy), releasing the $\mathrm{CO}_{2}$ absorbed during growth back into the atmosphere, but is reused (if still intact) or recycled. Considering that the current chain of 
chipboard and wood composites is very active, not only in the construction supply chain but also in the furniture supply chain, end-of-life recycling of structural wood is a plausible hypothesis. The project was therefore designed with a predominantly wooden structure, with pillars and floors in X-lam, in line with the design choices aimed at constructive reversibility and the potential reusability or recyclability of the entire construction (circular building).

From the point of view of system choices, to have an advantage in terms of carbon footprint, the choice must necessarily fall on the use of photovoltaic which can produce free energy from the sun. In this case, attention must be placed on effective positioning of the panels with respect to solar exposure so that the production of energy during use compensates for the production impact of the panel and allows for $\mathrm{CO}_{2}$ gains in terms of avoided impacts compared to the use of other sources.

In the later phases of the project, the contribution of environmental consultancy to project choices focused on more detailed aspects, trying to optimize the carbon footprint of the other parts of the building. The call requires a low-carbon building, compared to a "business as usual" (BAU) building. Consequently, the work setup was based on a comparison among technical solutions and design choices, demonstrating through LCA evaluation the "environmental gains" obtained from the project choices with respect to choices typically implemented in current practice.

The "background" data (EC-JRC 2012), related to the environmental LCI and LCA of building products, were derived from the Environmental Product Declaration (EN 15804:2012) and, only when the EPDs were not available for the specific component, from databases (Ecoinvent, Ökobaudat, Inventory of Carbon and Energy ICE). The choice to use primary data deriving from EPD is linked to the desire to identify low impact products not only by comparing alternative materials but also by selecting products with the lowest environmental impact within the same material compartment. The materials selected have a lower carbon footprint for their recycled content, their production process based on the principles of a circular economy (e.g., industrial ecology) or their plant matrix content (absorbers of $\mathrm{CO}_{2}$ during the growth of the plant). Transportation was also taken into consideration: for example, in the case of the concrete that constitutes the foundations, a more distant producer was chosen, but which guarantees a concrete with a lower environmental impact in the production process.

After the collection of $\mathrm{CO}_{2}$ data related to alternative solutions, the assessment considered the highest and lowest values of $\mathrm{CO}_{2}$ eq emissions related to the phases A1-A4 (A1-raw materials supply, A2-transport to the production plant, A3production, and A4-transport to the building site). For each part of the building considered, a comparison was made among possible materials and alternative producers, selecting the product with the lowest emissions (l.e.) and the product with the highest emissions (h.e.) among those (with EPD) present on the market; therefore, the material with the lowest emissions was selected (if compatible with the high-performance levels required by the project target). The database values were considered as a reference for the average values or assumed as comparison values only for materials without an EPD (Figs. 1 and 2). 

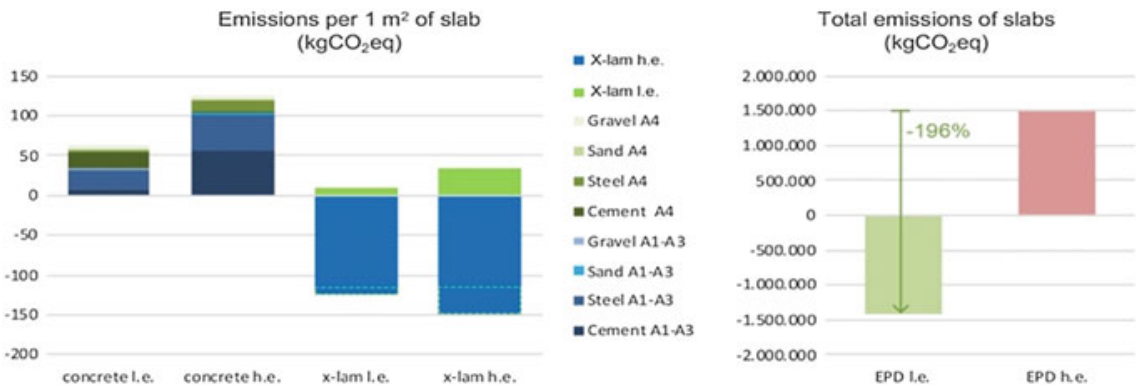

Fig. 1 LCA comparison, relating to $1 \mathrm{~m}^{2}$ of slab, among lowest emission products and highest emission products, based on EPD data, for different materials (reinforced concrete and X-lam) and LCA comparison between the total impacts (entire buildings) of the project choice (X-lam 1.e.) and BAU model (concrete h.e.)
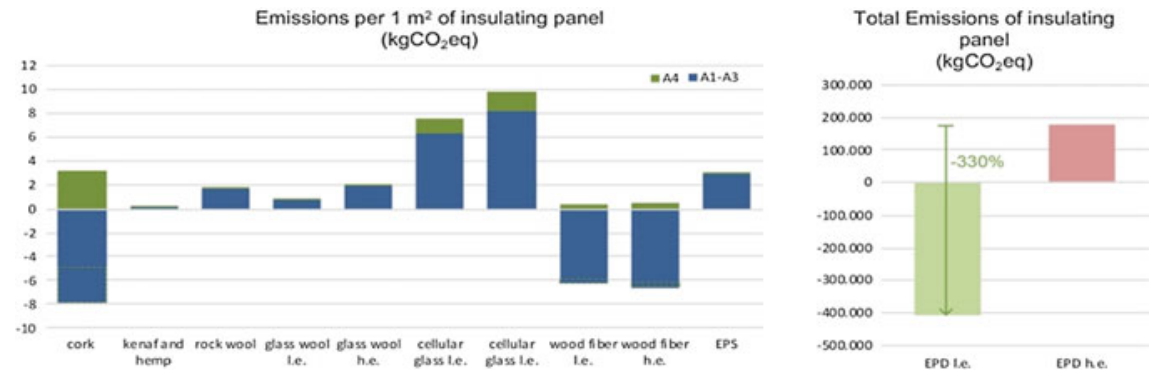

Fig. 2 LCA comparison, relating to $1 \mathrm{~m}^{2}$ of panel, among lowest emission products and highest emission products, based on EPD data, for different insulating materials and LCA comparison between the total impacts (entire buildings) of the project choice (wood fiber l.e.) and BAU model (EPS for slabs and rockwool for walls h.e.)

After the selection of the lower carbon materials, for each building part (loadbearing structure of foundation, retaining walls and stair core, pillars, beams, slabs, façade cladding, thermal insulation, vertical walls frame, interior covering panels, floor coverings, and window frames), a comparison was made between the design choice and the BAU material choice (assuming the worst design choices among those compared, as a precautionary approach), considering the total quantity of material in the entire intervention, and therefore evaluating the total reduction in emissions achieved by the project.

At the end of this process of assessments and design choices, an overall summary evaluation was carried out relating to the impacts of production and transportation of all the parts of the project, showing the comparison between project choice and BAU. As assumed in the preliminary phase, the supporting structure is the element that has the greatest influence and that determines the greatest environmental advantage.

With regard to the use phase, the energy consumptions assumed for the project are based on a water-water heat pump with geothermal probes, characterized by a COP 
$=4$ and electrically powered. The electricity is supplied via photovoltaic panels of $2037 \mathrm{~m}^{2}$, installed on site. In this case, the production of photovoltaic energy exceeds the requirements. For BAU model, the consumptions considered are related to the minimum mandatory requirement (so higher than the ones achieved by the project) and are connected to a heating system with a methane gas condensation boiler and a cooling system with an air-water heat pump characterized by a COP $=2.8$ and electrically powered. The production of electricity connected to photovoltaic panels of $243 \mathrm{~m}^{2}$, corresponding to the minimum surface area required by the Region of Lombardy, covers only a minimal part of the need for electricity, making it necessary to obtain energy from the electrical grid. As a result, there is a significant reduction in the impacts of the project. The calculation compares the impacts of the project, considering the production impact of the photovoltaic panels and two cycles of the photovoltaic panels replaced during the building life, and the impact of the BAU model, considering the electrical (national electricity mix) and thermal (methane) energy consumed (Figs. 3 and 4).

It should be pointed out that the environmental advantage achieved in the use phase, thanks to energy-saving strategies and the installation of plants for production from renewable sources, is considerably greater than those achieved in the production phase. In fact, in conventional buildings, high consumption (even in compliance with the current regulations on energy efficiency), and the use of fossil fuels (also for the production of electricity) determine considerable environmental impacts. At the same time, it must be emphasized that, in the future, when the legislation on zeroenergy building will be applied and it will become common practice to construct low consumption buildings with integrated systems for the production of energy from renewable sources, the impacts related to the production of materials (embodied carbon and embodied energy) will become increasingly important elements.

With regard to the maintenance phase, the replacement cycles of bathrooms and kitchens were considered. To facilitate maintenance operations, the project team

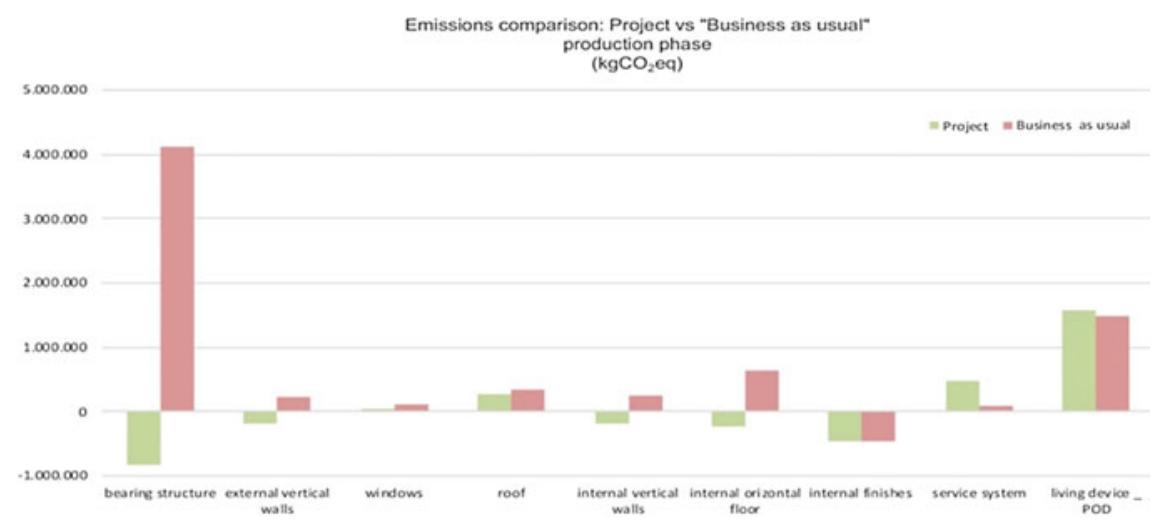

Fig. 3 LCA comparison, relating to the buildings as a whole and relating to production phase, between the design choice (green) and the BAU model (red), for each building part 


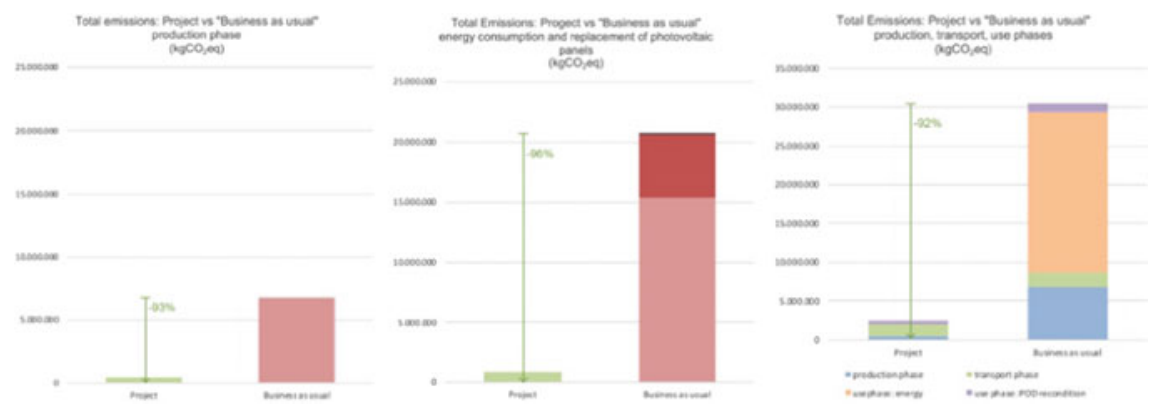

Fig. 4 LCA comparison relating to the buildings as a whole between the design choice (green) and the BAU model (red): to the left relating to the production phase of building materials, in the center relating to the use phase and systems production, and to the right relating to the entire life cycle

designed an innovative POD solution, such as reversible prefabricated cells, which can be disassembled, brought to the factory, "re-manufactured" and reassembled, reducing waste material and replacements, in view of a circular building perspective. The calculation accounted for the disassemblable POD in the project model and the traditional replacement of the systems in the BAU model. In the case of the POD, a deep-renovation maintenance cycle is planned every 20 years and, considering a useful life of 50 years, two renovation cycles are considered. During that operation, the load-bearing structure of the PODs is recovered by 100 and $50 \%$ of the materials and components subject to the renovation could be recovered. In the BAU case, it was considered that $100 \%$ of the materials and components subject to renewal would be replaced.

Contrary to what was expected, in this case, the environmental advantage obtained, although present, is small, since the structure of the POD (which ultimately is an "additional" element) significantly affects the carbon footprint (production impact of the steel frame). An in-depth analysis of the structural design of the POD, in order to optimize and reduce the amount of material used, could demonstrate a more advantageous environmental balance of the POD disassembly solution.

In the end, the reduction of $\mathrm{CO}_{2}$ eq emissions of the entire intervention was calculated, comparing two models: a project model and a BAU model. In the evaluation of the entire life cycle, the phases of production A1-A3, transport to building site A4, use B6 (energy consumption) and replacement B4 were considered. The construction phases and the end-of-life phase were not considered, both because these phases typically have a reduced incidence, about 2-4\% (Lavagna et al. 2018), and because in this particular project, the use of dry construction techniques allows for the fact that the impacts of the construction site both during construction and demolition are reduced (mechanical assembly activities only) and at the end of their life, most of the building materials can be reused or recycled as the building is completely reversible. The results obtained point out the virtuousness of the design choices that were made considering the $\mathrm{CO}_{2}$ eq emissions on different scales: from the material to the product, from the subsystem to the building. 
Finally, all the benefits-such as direct sequestration of $\mathrm{CO}_{2}$ and reduction of GHGs-deriving from the use of NBS were calculated in terms of $\mathrm{CO}_{2}$ eq. using values from the scientific literature and databases (database Qualiviva; CNT 2010; IPCC 2007; McPherson et al. 2006) and I-Tree Eco software (V.6).

All the adopted solutions-detailed and careful selection of construction (materials and supply model), management model, maintenance solutions and NBS-have made it possible to contain the impact of a building over 50 years to approximately $1.6 \mathrm{~kg} \mathrm{CO} \mathrm{CO}_{2} \mathrm{eq} / \mathrm{m}^{2}$ per year. To compensate this value, a forestry intervention on an area of fewer than 2 ha would be sufficient.

\section{Critical Aspects and Future Developments}

The experience of a real participation alongside a project team and in response to a call from a public body was definitely positive, because it shows a virtuous case of promotion of sustainability aspects by a public administration, which therefore urges the project team to consider the environmental aspects and leads to the involvement of environmental consultants in an effectively integrated way from the first phases of the project, in order to be able to achieve the ambitious goal required. However, it is also necessary to highlight the aspects that remain critical in this type of experience. In particular, the fact of having chosen a single environmental indicator (the carbon footprint), considered a priority in the international debate (Rockström et al. 2017), risks orienting the design choices in a direction that is not entirely sustainable.

As mentioned above, in order to reduce the carbon footprint of a building, the necessary choice is to use large amounts of wood in its construction. Some researchers show that a cross-laminated timber building gives the lowest life-cycle carbon emission while a beam-and-column building gives the highest life-cycle emission (Doodo et al. 2014). Although it might seem counterintuitive, the increasing of quantities in the case of wood, therefore abounding rather than optimizing, decreases the carbon footprint, since it increases the quantity of stored $\mathrm{CO}_{2}$ that becomes a minus in the environmental balance. However, by using more material unnecessarily, the project brings about a disadvantage compared to all the other environmental impact indicators (only in the case of the carbon footprint is there the possibility of having the minus sign in phases A1-A3 raw materials supply-transport to the production plant manufacturing).

Moreover, although different methodological choices and assumptions can lead to opposite conclusions, there is no consensus on the assessment of biogenic carbon in LCA. Incorrect biogenic carbon assessments could lead to inefficient or counterproductive strategies, as well as missed opportunities (Breton et al. 2018). There is a need for a government mandate for improved data quality and for support for the development of a transparent and simplified methodology (De Wolf et al. 2017). Therefore, making environmental choices by considering a single indicator is likely to indicate a constructive solution with respect to a single environmental theme, 
without considering the impacts related to other aspects (energy consumption, acidification, human toxicity, and soil consumption). For example, the wood supply chain is critical with respect to land use and acidification issues.

Hence, the actions promoted by public administrations should reconcile the need for a simplified approach (also for checking the results obtained by the project) with a complete environmental approach, which requires a systemic capability to control environmental impacts in their complexity.

\section{References}

Breton, C., Blanchet, P., Amor, B., Beauregard, R., \& Chang, W. S. (2018). Assessing the climate change impacts of biogenic carbon in buildings: A critical review of two main dynamic approaches. Sustainability, 10(6), 2020.

CNT. (2010). The value of green infrastructure. A guide to recognizing its economic, environmental and social benefits. Center for Neighborhood Technology.

De Wolf, C., Pomponi, F., Moncaster, A. (2017). Measuring embodied carbon dioxide equivalent of buildings: A review and critique of current industry practice. Energy and Building, 140, 68-80.

Dodoo, A., Gustavsson, L., \& Sathre, R. (2014). Lifecycle carbon implications of conventional and low-energy multi-storey timber building systems. Energy and Building, 82, 194-210.

EC-JRC. (2012). The international reference Life cycle data system (ILCD) handbook. Towards more sustainable production and consumption for a resource efficient Europe. European Commission, Joint Research Centre, Luxembourg

EN 15804:2012 Sustainability of construction works. Environmental product declarations. Core rules for the product category of construction products.

EN 15978:2011 Sustainability of construction works. Assessment of environmental performance of buildings. Calculation method.

Fouquet, M., Levasseur, A., Margni, M., Lebert, A., Lasvaux, S., Souyri, B., et al. (2015). Methodological challenges and developments in LCA of low energy buildings: Application to biogenic carbon and global warming assessment. Building and Environment, 90, 51-59.

IPCC. (2007). Climate change 2007: Mitigation. In B. Metz, O. R. Davidson, P. R. Bosch, R. Dave, L. A. Meyer (Eds.), Contribution of working group III to the fourth assessment report of the Intergovernmental Panel on Climate Change. Cambridge University Press

Lavagna, M., Baldassarri, C., Campioli, A., Giorgi, S., Dalla Valle, A., Castellani, V., et al. (2018). Benchmarks for environmental impact of housing in Europe: Definition of archetypes and LCA of the residential building stock. Building and Environment, 145, 260-275.

Lehmann, U., Khouryb, J., \& Patel, M. K. (2017). Actual energy performance of student housing: Case study, benchmarking and performance gap analysis. Energy Procedia, 122, 163-168.

McPherson, E. G., Simpson, J. R., Peper, P. J., Maco, S. E., Gardner, S. L., Cozad, S. K., et al. (2006). Midwest community tree guide. Benefits, costs, and strategic planting. Create space Independent Publishing.

Rockström, J., Gaffney, O., Rogelj, J., Meinshausen, M., Nakicenovic, N., \& Schellnhuber, H. J. (2017). A roadmap for rapid decarbonisation. Science, 355, 1269-2127.

Skullestad, J. L., Bohne, R. A., \& Lohne, J. (2016). High-rise timber buildings as a climate change mitigation measure: A comparative LCA of structural system alternatives. Energy Procedia, 96, $112-123$.

Van Dronkelaar, C., Dowson, M., Burman, E., Spataru, C., \& Mumovic, D. (2016). A review of the energy performance gap and its underlying causes in non-domestic buildings. Frontiers in Mechanical Engineering, 1, 1-14. 
Open Access This chapter is licensed under the terms of the Creative Commons Attribution 4.0 International License (http://creativecommons.org/licenses/by/4.0/), which permits use, sharing, adaptation, distribution and reproduction in any medium or format, as long as you give appropriate credit to the original author(s) and the source, provide a link to the Creative Commons license and indicate if changes were made.

The images or other third party material in this chapter are included in the chapter's Creative Commons license, unless indicated otherwise in a credit line to the material. If material is not included in the chapter's Creative Commons license and your intended use is not permitted by statutory regulation or exceeds the permitted use, you will need to obtain permission directly from the copyright holder.

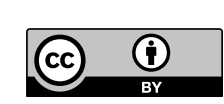

